Transactions of the 13th International Conference on Structural Mechanics in Reactor Technology (SMiRT 13), Escola de Engenharia - Universidade Federal do Rio Grande do Sul, Porto Alegre, Brazil, August 13-18, 1995

\title{
Seismic safety of nuclear power plants in Eastern Europe
}

Godoy, A., Gürpinar, A. International Atomic Energy Agency, Vienna, Austria

ABSTRACT: The paper provides an insight to the seismic evaluation and upgrading programmes of existing WWER-type nuclear power plants in Eastern European countries, with particular emphasis on the criteria being applied, as well as the major lessons learnt.

\section{INTRODUCTION}

The concern on the safety level of existing nuclear power plants in Eastern Europe came into focus a few years ago. One of the major reasons for this concern was the recognition that some site-related external events were not properly considered in the original plant design.

Particularly, the seismic safety of nuclear power plants in Eastern Europe has received renewed attention after the recent political and social changes. The principal reason for this was the need to compare the criteria, standards and methods used to establish seismic safety in eastern European nuclear power plants with those generally accepted in international practice.

seismic safety issues generally involve two major components; those related to the derivation of the design basis parameters (i.e. seismic input) and those involving the seismic capacity of structures, equipment and distribution systems. Regarding the first component, although most Eastern European nuclear power plant sites can be characterized as low to medium seismicity sites, the deficiency in the tectonic and seismic database as well as the methods used in the 1970 s have led to hazard re-evaluation programmes. The results of the new studies consistently indicate that the design basis ground motion parameters had been underestimated, sometimes by a considerable margin.

The issues related to the seismic capacity of structures, equipment and distribution systems are even more complex. For WWER and RBMK type nuclear power plants, structures which do not function as a pressure boundary are designed like conventional industrial frame buildings, often using precast concrete elements. In WWER 440 and RBMK type nuclear power plants, the 'confinement' concept restricts the pressure boundaries to the lower part of the reactor building. WWER 1000 type plants, however, have a proper structural containment and therefore are inherently better designed for external events in general.

The involvement of the IAEA in the seismic safety isgues of Eastern Europe has been substantial through national, regional and extrabudgetary projects. Seismic safety review missions visited nuclear power plants in Armenia, Bulgaria, Czech Republic, Hungary, Poland, Romania, Russian Federation, Slovakia, Slovenia and Ukraine within the past five years. 


\section{SEISMIC RE-EVALUATION PROGRAMMES}

The re-assessment of the seismic capacity of existing facilities is due to the following reasons: (a) evidence of seismic hazard at the site higher than what was expected before, through more available data, new methods and new experience from real earthquakes; (b) the existing facility was not explicitly designed and constructed to withstand seismic loads; (c) regulatory requirements stricter than the ones valid at the time of design and construction.

These reasons lead to the definition of a post-construction safety evaluation earthquake, called "review level earthquake" (RLE), and experience shows that this earthquake is usually larger than the one for which the facility was originally designed.

A seismic re-evaluation programme has three major components, (i) the re-assessment of the seismic hazard as an external event; ( $i i$ ) the evaluation of the plant specific seismic capacity to withstand the loads generated by such event, and (iii) the implementation of upgrades to buildings and components, if needed.

Figure 1 shows the general flow diagram for the seismic reevaluation process, which starts with the assessment of the original seismic input.

The result of the re-evaluation of the seismic hazard at the WWER type reactor sites in Eastern European countries is given in Table 1. Regarding the first component, the geological stability and the ground motion parameters are assessed according to specific site conditions and in compliance with criteria and methods valid for new facilities, which means in accordance with criteria established by the IAEA Safety Guide 50-SG-SI (Rev. 1). Therefore the RLE should correspond to the SL-2 level, directly related to ultimate safety requirements, that is a level of extreme ground motion that shall have a very low probability of being exceeded during the plant lifetime and represents the maximum level to be used for design and re-evaluation purposes. The recommended minimum level is a peak ground acceleration of $0.10 \mathrm{~g}$ for the zero period of the design response spectrum. For the probability of occurrence a typical value of $10^{-4} / \mathrm{yr}$ is usually used and for the ground response spectra an elastic one is selected.

Considering that these investigations need a long time for completion, a conservative preliminary value of the RLE may be assumed for starting the activities related to the re-evaluation of the seismic capacity and upgrading of plant systems, structures and components. This may be called interim RLE (iRLE).

Another important consideration for re-evaluation purposes only is that if median plus one standard deviation was used for the definition of the peak ground acceleration, a median shaped elastic response spectra as given in US-NUREG/CR-0098 is permitted.

\section{CRITERIA FOR RE-EVALUATION OF SEISMIC CAPACITY}

In relation to the second component of the programme mentioned in Section 2, the objective is to enhance the seismic safety in compliance with valid standards and recognized practice, using (a) realistic as-built data; (b) less conservative criteria and methods than the ones used in the design process for at least those functions, systems, components and structures required to ensure safe shutdown and to maintain it in safe shutdown conditions. This is often a subset of the structures, systems, and components important to safety. This practice effectively ensures that a kind of "dedicated, earthquake-hardened safe shutdown systems" exists at the plant.

Figure 2 provides the flow diagram of the detajled work plan indicating sequence, relationship and interdependence between different tasks. The main steps and criteria used are as follows: 
3.1 Identification and classification of seismic safety functions, systems and components

The main criteria and assumptions as indicated by international practice are:

(a) the plant must be capable to be brought to and maintained in a safe shutdown condition during the first 72 hours following the occurrence of the RLE;

(b) safe shutdown means hot or cold shutdown;

(c) simultaneous offsite power loss occurs for up to 72 hours;

(d) the required safe shutdown systems should fulfill single active failure criterion;

(e) loss of make-up water capacity from offsite sources occurs for up to 72 hours;

(f) other external events such as fires, flooding, tornadoes, sabotage, etc. are not postulated to occur simultaneously;

(g) Loss of Coolant ACcident (LOCA) and High Energy Line Breaks (HELB) are not postulated to occur simultaneously.

The seismic safety essential list (SSEL) is the list of equipment required for the minimum selected set of seismic safety systems and is an important result of this step.

\subsection{Plant walkdown}

Emphasis should be given to the collection and compilation of original design basis data and documentation in order to minimize the efforts required for the re-evaluation programme. However, in any case a plant walkdown should be performed to get information on asbuilt conditions and to assess the seismic capacity of equipment.

The main focus of the walkdown is on anchorage of the equipment; load path from the anchorage up through the equipment; the equipment structure; and spatial systems interactions.

In general, there will be three alternative disposition categories for each structure, system and component being evaluated during the walkdown:

(1) Disposition 1: a $f$ ix is required;

(2) Disposition 2: the seismic capacity is uncertain and an evaluation is needed to determine if a $f i x$ is required, and

(3) Disposition 3: the seismic capacity is adequate for the specified RLE and the items appear to be seismically rugged.

The three alternate dispositions are primarily based on judgement and the walkdown teams must be experienced in order to make these judgements.

Screening guidelines are used to determine if the components are represented by the experience database and applies to the component in question. Unfortunately, most of the components and distribution systems in the WWER type rectors were manufactured by organizations for which seismic and testing experience has not been gathered and reviewed. Similarity analysis should, therefore, be made.

\subsection{Evaluation of seismic margin capacity}

The concept of High Confidence of Low Probability Failure (HCLPF) capacity is used in the seismic margin assessment to quantify the seismic margins of NPPs. In simple terms it corresponds to the earthquake level at which, with high confidence ( $\geq 958$ ) it is unlikely (i.e. $\leq 58$ ) that failure of a system, structure or component required for safe shutdown of the plant will occur.

(a) The first step in estimation of HCLPF seismic capacity is to develop a clear definition of what constitutes failure for each of the systems, structures and components being evaluated. Several modes of seismic failure may have to be considered. It may be possible to identify the failure mode which is most likely or the most dominant to be caused by the seismic event by reviewing the SSC design and to consider only that mode. 
(b) The response analysis for RLE will be conducted with the values of appropriate damping ratios, which may be used if the stresses in the majority of resisting building elements for the applicable loading combination are greater than 508 of ultimate strength for concrete or yield capacity for steel (i.e. Stress Level 2). The use of higher damping values, if properly justified and determined, is also permitted.

(c) Nearly all structures and components exhibit at least some ductility (i.e., ability to strain beyond the elastic limit) before failure or even significant damage.

The inelastic energy absorption ratio, $F_{Y}$, is related to the amount of inelastic deformation that is permissible for each type of structural element. The additional seismic margin due to this inelastic energy absorption ratio (or ductility) should be considered in any margin review. In most cases, it is feasible to use linear elastic analysis techniques. When linear elastic analysis is applied, the easiest way to account for the inelastic energy absorption capability is to reduce seismic response by the $F_{u}$ factor. $F_{u}$ is defined as the amount that the elastic-computed seismic demand may exceed the capacity of the component without impairing its performance. It means that for non-brittle (ductile) failure mode inelastic distortion associated with a demand-capacity ratio greater than unity is permissible.

Standard $F_{U}$ values for different structural systems as being accepted for WWER type plants are determined considering two conditions: (i) the verification of seismic capacity of e" isting structures and components at WWER type reactors; and (ii) the verification of seismic capacity of structures designed using joint ductile requirements as established in applicable codes.

(d) Seismic response of building structures will be evaluated on the basis of dynamic analysis of models of the soil-structure system. In order to develop appropriate structural models special attention is given to (a) structural configuration and construction details (joints, gaps, restraints and supports); (b) non structural elements, such as masonry or precast reinforced concrete panels that may modify the structure response. Stiffness and strength of such panels, and those of their attachments to the structure, should be accounted for in the formulation of the models; (c) as-built material properties and dimensions of structural members; (d) geotechnical data of foundation materials and their potential implications on the necessity to perform soil-structure interaction analysis, for which direct methods are usually being applied. For soil-structure interaction analysis radiation damping will not be limited but resultant composite modal damping should not exceed 20.08 .

(e) Combinations of seismic and non-seismic loads shall be made according to the specific equations (for reinforced concrete structural elements, for masonxy walls and precast reinforced concrete panels, component pressure boundaries, supports for piping and pressure components and cable raceways).

(f) An earthquake experience and test based judgmental procedure to verify the seismic adequacy of the specified safety-related equipment in operating NPPs using seismic experience methods, was developed in USA to address regulatory requirements for requalification of older plants. The procedure is primarily based upon the performance of installed mechanical and electrical equipment which have been subjected to actual strong motion earthquakes as well as upon the behaviour of equipment components during simulated seismic tests. With a number of caveats and exclusions for excitations below spectra normalized to $0.3 \mathrm{~g}$ and in some cases $0.5 \mathrm{~g}$, for the ZPGA, it is unnecessary to perform explicit seismic analysis or test qualification of existing equipment to demonstrate functionality after the strong shaking has ended. The existing data base reasonably demonstrates the seismic ruggedness of existing equipment up to these seismic motion bounds. This conclusion should not be extrapolated beyond the classes of equipment existing in the database.

(g) The presence of adequate anchorage is perhaps the most 
important single item which affects the seismic performance of distribution systems and components, which can slide, overturn, or move excessively when not properly anchored. Adequate strength of system and component anchorage can be determined by any one of many commonly accepted methods. The load or demand on the anchorage system can be obtained from the floor response spectral acceleration for the prescribed damping value and at the estimated fundamental or dominant frequency of the system or component. A conservative estimate of the spectral acceleration may be taken as the peak of the applicable spectra. This acceleration is then applied to the mass of component or gystem at its center of gravity.

Generally, the four main steps for evaluating the seismic adequacy of equipment anchorage include: anchorage installation inspection; anchorage capacity determination; seismic demand determination; and comparison of capacity to demand.

(h) In addition to the inertia effects there may also be significant secondary stresses induced in systems and components by differential or relative anchor motion if the system or component is supported or restrained at two or more points. For supports it is common practice to evaluate such seismic induced anchor motion, where the relative or differential motion of the building structure at the different points of attachment should be input to a model of the multiple supported component or system. Resultant forces, moments and stresses in the support system determined from the seismic anchor motion effects acting alone shall meet the same limits for normal operation plus RLE inertia stresses.

\subsection{SUMMARY AND CONCLUSIONS}

Considerable amount of effort in software (analysis) and hardware (upgrading) has been made to increase the safety level of existing NPPs in relation to external events in Eastern European countries. "Real" upgrading was already performed to cope with higher seismic loads. During this process, an international consensus on a more unified acceptance criteria for re-evaluation and upgrading is being obtained. However, there are still some problems and doubts in relation to (a) the retrieval and understanding of the original design data and qualification test data for components, (b) the compliance of the existing components with those of the database being used, (c) the co-ordination between all parties involved, and (d) finally, the actual performance of these upgraded facilities to a real earthquake.

\section{REFERENCES}

IAEA Safety Series No. 50-SG-S1 (Rev. 1) Guide 1991. Earthquake and associated topics in relation to nuclear power plant siting.

Newmark, N.M. and Hall, W.J. May 1978. Development of criteria for seismic review of selected nuclear power plants. NUREG/CR-0098.

Table 1: Seismic Design Basis (SDB) for NPPs in Eastern Europe (Seclected)

\begin{tabular}{|l|l|c|l|}
\hline \multicolumn{1}{|c|}{ Plant } & \multicolumn{1}{|c|}{ Country } & $\begin{array}{c}\text { Original SDB } \\
\text { (pga) }\end{array}$ & $\begin{array}{c}\text { Re-assessed SDB } \\
\text { (pga) }\end{array}$ \\
\hline Kozloduy & Bulgaria & $\mathrm{N} . \mathrm{E} . \mathrm{D}$. & $0.2 \mathrm{~g}$ \\
Bohunice & Czech Republic & $\mathrm{N.E.D.}$ & $0.25 \mathrm{~g}$ (continuing) \\
Mochovce & Slovakia & $0.05 \mathrm{~g}$ & $0.1 \mathrm{~g}$ (continuing) \\
Belene & Bulgaria & $0.1 \mathrm{~g}$ & Continuing \\
Cernavoda & Romania & $0.15 \mathrm{~g}$ & No re-assessment \\
Paks & Hungary & $\mathrm{N.E.D.}$ & $0.35 \mathrm{~g}$ (continuing) \\
Krsko & Slovakia & $0.3 \mathrm{~g}$ & Continuing \\
Temelin & Czech Republic & $0.06 \mathrm{~g}$ & $0.1 \mathrm{~g}$ \\
Medzamor & Armenia & $0.1 \mathrm{~g}$ & $0.4 \mathrm{~g}$ (continuing) \\
\hline
\end{tabular}

N.E.D.: Not explicitly designed against seismic loads 
Figure 1: Flow diagram for seismic re-evaluation and grading of existing NPPs
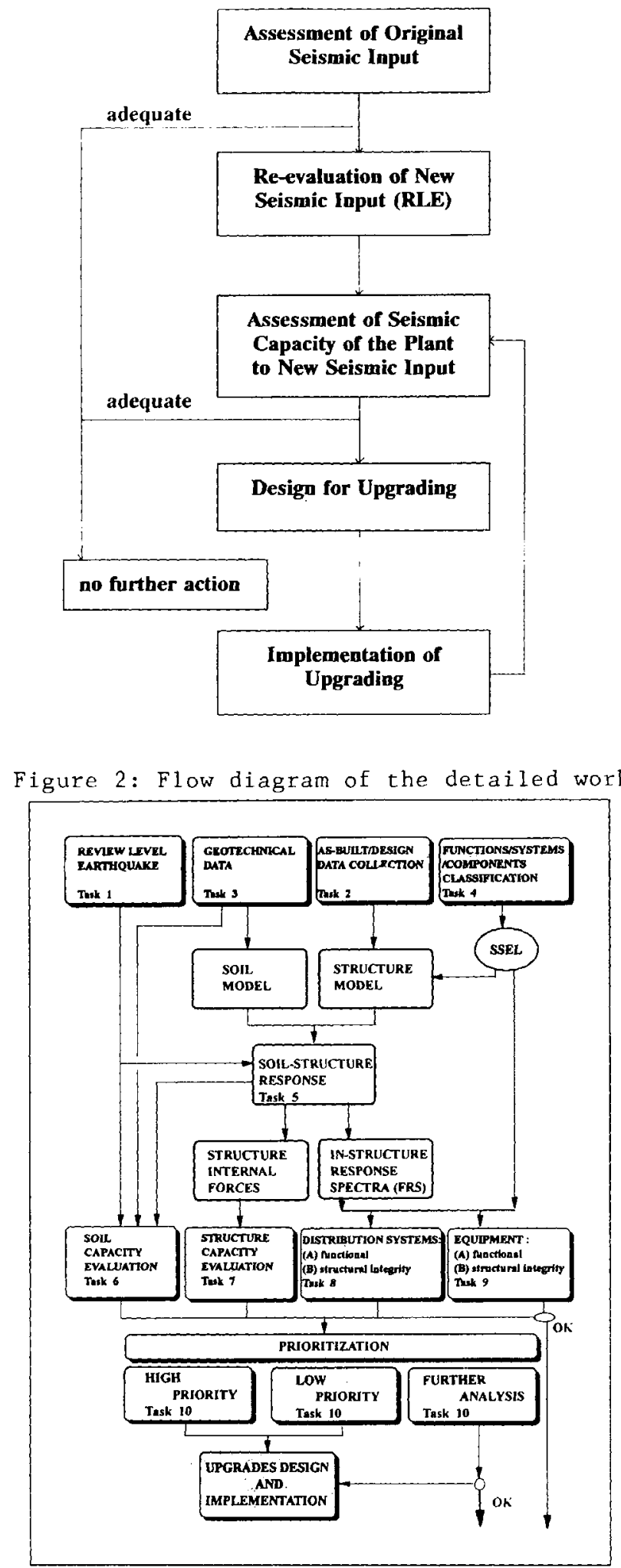